\title{
Use of Latest Robots for Autism Spectrum Disorder
}

\author{
Sara Ali*, Yasar Ayaz and Muhammad Jawad Khan \\ Department of Robotics and Intelligent Machine Engineering, SMME, National University of Sciences and Technology, Pakistan
}

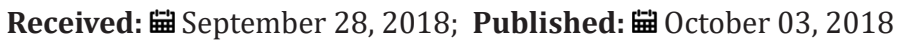

*Corresponding author: Sara Ali, Department of Robotics and Intelligent Machine Engineering, SMME, National University of Sciences and Technology, Islamabad, Pakistan

\begin{abstract}
One of the prominent applications of robots is in assistive therapy using humanoids. Robots are now playing a vital role in our lives as assistants, therapist, companions and much more. Autism Spectrum Disorder (ASD) affects the communication skills and social cues of a person considerably. Recently efforts have been made in the development of communicational, behavioral, motor movements, joint attention and physical behavior of the children suffering from ASD using the humanoid robots. The therapies based on interactive interventions using robots for ASD have proved to be a favorable tool for improving the behavior of children with ASD. There are different ways to identify and improve the behavior in ASD child e.g. psychologists' sessions, computer vision based bio markers like joint attention measurement and gait analysis, and robot assisted therapies using Autism Observation Scale for Infants (AOSI). In particular the area of robotics is helping a lot in the treatment of ASD as the robot acts as a mediator as well as measures the response of an autistic child.
\end{abstract}

Keywords: Autism; Joint Attention; Therapy; Bio Markers

\section{Introduction}

Socially assistive robots (SAR) are becoming a part of therapies for the treatment of Autism spectrum disorder. The SAR aims at improving the social response and communication skills of an individual suffering with social disabilities. One of the most commonly addressed disabilities by the humanoid robots is Autism Spectrum Disorder (ASD) [1]. Impairment in social interactions and communication skills caused by a complex developmental brain disorder refers to the definition of Autism Spectrum Disorder [2]. Children under ASD lack verbal, non-verbal and communication skills such as joint attention, imitation, gait, motor skills, facial expressions etc. With the advancement in recent years, robots are now replacing human tasks with a lot of accuracy, reliability, different aesthetic and functional characteristics. Robots have now been interacting with ASD children under specially designed interactive interventions for improving the social cues and behavior of ASD child. There are several robots that have been made to develop social development skills or physical impairments. Research shows that robots helps to improve the attention span and develop the spontaneous skills of a child with ASD $[3,4]$. Examples of such robots are Paro [5-7], robotic doll Robot [8-11]. These robots help people with physical, emotional and behavioral disorders to improve their social interaction and cues.

\section{Robots Utilized in ASD Interventions}

Table 1: Commonly used robots in autism spectrum disorder therapies.

\begin{tabular}{|c|c|c|c|}
\hline Robot Name & NAO & iRobi & Robotics OP2 \\
\hline Height $(\mathrm{cm})$ & 53 & 32 & 45.45 \\
\hline Weight $(\mathrm{kg})$ & 4.3 & 7 & 3.0 \\
\hline DOF & 25 & & 20 \\
\hline CPU & Intel Atom $61.6 \mathrm{GHz}$ & Celeron $6733 \mathrm{MHz}$ & $\begin{array}{l}\text { Intel Atom N2600@1.6 GHz (dual } \\
\text { core) }\end{array}$ \\
\hline CPU additional accessory & & $256 \mathrm{MB}, \mathrm{HDD} 40 \mathrm{~GB}$ & 4 GB DDR3, 32 GB mSATA \\
\hline Operation Time & 90 minutes (LIPO battery) & 180 minutes (LIPO battery) & 30 minutes (LIPO battery) \\
\hline Built in $O S$ & NAOqi 2.0 (Linux based) & & $\begin{array}{l}\text { Any Linux or Windows release (32 bit } \\
\text { only) }\end{array}$ \\
\hline Compatible OS & Windows, MAC and Linux & & Linux and Windows (32 bit) \\
\hline Programming Languages & $\begin{array}{l}\text { C++, Java, MATLAB, Urbi, C, .Net, } \\
\text { Python }\end{array}$ & & \\
\hline Sensors & $\begin{array}{l}\text { Two HD cameras, four microphones, } \\
\text { sonar rangefinder, two infrared emit- } \\
\text { ters and receivers, inertial board, nine } \\
\text { tactile sensors, eight pressure sensors }\end{array}$ & $\begin{array}{l}\text { Camera, Microphone, } 7 \text { Ultrasonic } \\
\text { sensors, Inertial unit, } 12 \text { IR sensors, } \\
\text { Floor detection sensor, } 2 \text { stereo speak- } \\
\text { ers, stereo Mac, } 7 \text { inch Touch screen, } \\
6 \text { Tactile sensors }\end{array}$ & $\begin{array}{l}\text { Serial communication, } 2 \text { USB ports, } \\
3 \text { axis-gyro, } 3 \text { axis-accelerometer, } 2 \\
\text { microphones }\end{array}$ \\
\hline Connectivity & Wifi, Ethernet & $\begin{array}{l}\text { Wireless LAN installed for internet } \\
\text { connection }(101.11 \mathrm{~b} / \mathrm{g})\end{array}$ & Ethernet, mini HDMI \\
\hline Cost (US) & 7996 & 4598 & 9600 \\
\hline
\end{tabular}


There are multiple robots which have been developed and utilized in Autism Spectrum Disorder curing. Few of them are given in Table 1, which are listed along with their specifications. Among all, NAO is more famous and it's being utilized in different applications along with Autism Spectrum Disorder.

\section{References}

1. S Mohammad Mavadati, Huanghao Feng, Anibal Gutierrez, Mohammad H Mahoor (2014) Comparing the Gaze Responses of Children with Autism and Typically Developed Individuals in Human-Robot Interaction. IEEE, Spain.

2. S Baron Cohen (2004) The cognitive neuroscience of autism. Journal of Neurology, Neurosurgery \& Psychiatry 75(7): 945-948.

3. I Werry, K Dautenhahn, W Harwin (2001) Evaluating the response of children with autism to a robot, in Proc. of the RESNA 2001 Annual Conference, Rehabilitation Engineering and Assistive Technology Society of North America, Resna Press p.14-19.

4. H Kozima, C Nakagawa, Y Yasuda (2007) Children-robot interaction: A pilot study in autism therapy. Progress in Brain Research 164: 385-400.

5. K Wada, T Shibata (2006) Robot Therapy in a Care House-Its Sociopsychological and Physiological Effects on the Residents, in Proceedings of the International Conference on Robotics and Automation, pp. 3966-3971.
6. P Marti, A Pollini, A Rullo, T Shibata (2005) Engaging with artificial pets, in Annual Conference of the European Association of Cognitive Ergonomics, Chania, Greece.

7. H Kozima, H Yano (2001) Designing a robot for contingency detection game, in Workshop on Robotic and Virtual Interactive Systems in Autism Therapy.

8. A Billard, B Robins, K Dautenhahn, J Nadel (2006) Building Robota, a Mini-Humanoid Robot for the Rehabilitation of Children with Autism, RESNA Assistive Technology Journal 19(1): 37-49.

9. K Dautenhahn, A Billard (2002) Games Children with Autism Can Play with Robota, a Humanoid Robotic Doll, in Universal Access and Assistive Technology S Keates, et al. (Eds.); London: Springer-Verlag pp.179-190.

10. B Robins, K Dautenhahn, J Dubowski (2006) Does appearance matter in the interaction of children with autism with a humanoid robot? Interaction studies: Social Behaviour and Communication in Biological and Artificial Systems 7(3): 509-542.

11. K Dautenhahn, CL Nehaniv, ML Walters, B Robins, H Kose Bagci et al. (2009) KASPAR-A Minimally Expressive Humanoid Robot for HumanRobot Interaction Research, Special Issue on Humanoid Robots, Applied Bionics and Biomechanics 6(3-4): 369-397.
(C) Commons Attribution 4.0 License

To Submit Your Article Click Here: Submit Article

DOI: 10.32474/ARME.2018.01.000108

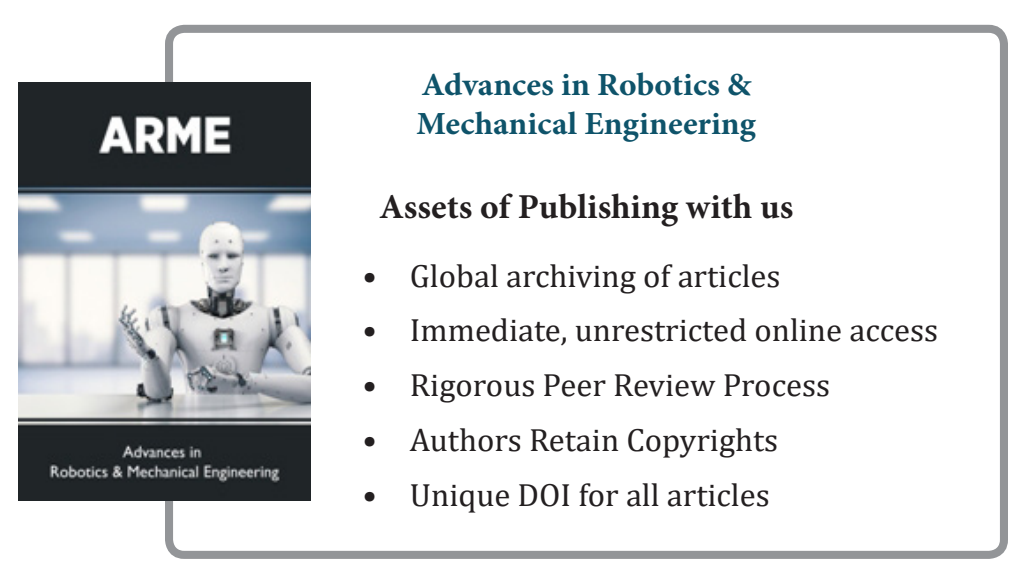

